INRA Prod. Anim., 2007, 20 (3), 191-198

\title{
Les techniques de diagnostic en santé des espèces aquacoles : intérêt et limites
}

\author{
C. MICHEL ${ }^{1}$, J.-F. BERNARDET ${ }^{1}$, J. CASTRIC 2 , J.-P. JOLY ${ }^{3}$ \\ ${ }^{1}$ INRA, UR892 Virologie et Immunologie Moléculaires, F-78352 Jouy-en-Josas, France \\ 2 AFSSA, Etudes et Recherches en Pathologie des Poissons, BP 70, F-29280 Plouzané, France \\ 3 IFREMER, Génétique et Pathologie, F-17390 La Tremblade, France \\ Courriel : Christian.Michel@jouy.inra.fr
}

Toute approche des maladies animales, incluant celles qui surviennent chez les espèces aquatiques, est indissociable de la démarche diagnostique. Initialement commandée par la nécessité de reconnaître, de distinguer et de caractériser les causes de maladies, celle-ci s'est élargie avec le développement intensif des élevages et la multiplication des échanges commerciaux, en intégrant notamment un souci de détection précoce des agents pathogènes pour permettre, hors de tout contexte clinique, de prévenir ou de limiter leur dissémination et propagation. C'est à ces seuls aspects que nous limiterons cet exposé, bien qu'au sens large le diagnostic intègre aussi l'observation clinique de terrain, le typage des bioagresseurs, et l'appréciation de leur sensibilité aux actions thérapeutiques envisageables.

Dans cette optique, les laboratoires de diagnostic se trouvent actuellement devoir répondre à deux grands types de préoccupations qui n'ont a priori ni les mêmes objectifs ni la même portée, et qui incluent chacun un éventail de démarches et de techniques pouvant leur être communes mais n'y prenant pas la même valeur. Ces techniques ont pour caractéristiques une évolution rapide et des indications précises, dictées à la fois par leurs performances, par le contexte dans lequel s'inscrivent les troubles observés, et par le type d'interrogations auquel elles sont censées répondre.

\section{1 / Considérations influen- çant le choix des méthodes de diagnostic}

Le contexte dans lequel s'expriment leurs actions apporte des indications précieuses sur la nature possible des agents affectant les animaux aquatiques, et partant, sur l'éventail des démarches qui pourront être mises en oeuvre pour les diagnostiquer. Les dominantes pathologiques, selon qu'on se trouve en milieu marin ou dulçaquicole, dans des structures de production intensive ou extensive, établies dans un système hydrologique ouvert ou clos, voire indépendantes des eaux de surface et fonctionnant en recyclage, ne sont effectivement pas les mêmes. Pareillement, la nature des espèces affectées, qu'il s'agisse de poissons de rente, de poissons ornementaux, ou d'invertébrés (mollusques ou crustacés) peut orienter les soupçons vers des agents ou des groupes d'agents pathogènes plus ou moins spécifiques.

Les informations dont on dispose à propos de ces agents pathogènes sont évidemment déterminantes dans la mise en oeuvre du diagnostic. On devra tenir compte des connaissances plus ou moins précises accumulées sur l'étiologie des diverses maladies, de l'instabilité des classifications ayant actuellement cours dans certains domaines du monde vivant, des données relatives à la biologie de certains microorganismes (ceux en particulier qui sont soupçonnés de transmission verticale par infection in ovo), et bien entendu, du caractère cultivable et des caractéristiques antigéniques de agents pathogènes considérés puisque de nombreuses méthodes de caractérisation reposent précisément sur ces propriétés.

Les objectifs de la consultation, nous l'avons dit, représentent enfin un critère déterminant dans le choix des méthodes. Un cas clinique déclaré n'imposera pas les mêmes contraintes qu'une demande de détection systématique, $a$ fortiori si cette dernière est commandée par l'application d'une réglementation officielle.

\section{2 / Aperçu des méthodes de diagnostic employées}

En tenant compte de tous les éléments auxquels le laboratoire d'analyse (ou l'analyste) peut avoir accès on peut classer les méthodes comme suit :

- Examen clinique et lésionnel, étayé par les commémoratifs joints à l'envoi d'animaux malades et si possible vivants ;

- Isolement et techniques culturales ;

- Observation directe sur échantillons cliniques ou après purification en microscopie, colorations, électromicroscopie ;

- Histopathologie ;

- Examen en microscopie électronique à transmission ;

- Méthodes immunologiques :

- sérologie

- immunomarquages ;

- Méthodes moléculaires ;

- Pouvoir pathogène expérimental.

En pratique, la nature des prélèvements reçus n'autorise pas toujours l'examen clinique, et l'inoculation expérimentale d'animaux est limitée à des cas exceptionnels. Les autres méthodes constituent l'arsenal classique du diagnostic de laboratoire. Le choix d'une méthode sera cependant conditionné par des considérations qui ressortent entièrement de l'expérience et des moyens du diagnosticien. Avant toute application, on s'interrogera plus particulièrement sur la fiabilité de la technique et son adéquation à la question posée, sur sa commodité de mise 
Tableau 1. Caractéristiques des différentes méthodes employées en diagnostic des maladies d'animaux aquatiques.

\begin{tabular}{|c|c|c|c|c|c|c|c|}
\hline Méthode & $\begin{array}{c}\text { Type } \\
\text { d'application }\end{array}$ & Spécificité & Sensibilité & Agents concernés & Rapidité & Coût & $\begin{array}{l}\text { Méthode } \\
\text { de référence }\end{array}$ \\
\hline Culture & $\begin{array}{l}\text { générale } \\
\text { ou ciblée }\end{array}$ & cas rare & variable & $\begin{array}{c}\text { virus, bactéries, } \\
\text { mycètes, } \\
\text { Perkinsus }\end{array}$ & non & modéré & oui \\
\hline $\begin{array}{l}\text { Etat frais } \\
\text { et empreintes }\end{array}$ & $\begin{array}{l}\text { générale } \\
\text { ou ciblée }\end{array}$ & médiocre & médiocre & $\begin{array}{c}\text { bactéries, mycètes, } \\
\text { parasites }\end{array}$ & oui & faible & non \\
\hline Histopathologie & $\begin{array}{l}\text { générale } \\
\text { ou ciblée }\end{array}$ & médiocre & médiocre & tous & non & moyen & «microcells» \\
\hline $\begin{array}{l}\text { Microsc. } \\
\text { électronique }\end{array}$ & exceptionnelle & médiocre & médiocre & $\begin{array}{c}\text { virus, } \\
\text { «microcells» }\end{array}$ & non & élevé & non \\
\hline $\begin{array}{l}\text { Immuno- } \\
\text { fluorescence }\end{array}$ & ciblée & bonne & bonne & $\begin{array}{l}\text { virus, bactéries, } \\
\text { protistes }\end{array}$ & oui & moyen & non \\
\hline ELISA & ciblée & bonne & bonne & $\begin{array}{l}\text { virus, bactéries, } \\
\text { protistes }\end{array}$ & oui & moyen & non \\
\hline $\begin{array}{l}\text { Immuno- } \\
\text { histochimie }\end{array}$ & ciblée & très bonne & bonne & virus, bactéries & oui & élévé & non \\
\hline PCR, RT-PCR & ciblée & très bonne & excellente & tous & oui & élevé & non \\
\hline PCR-RFLP & ciblée & très bonne & excellente & $\begin{array}{l}\text { bactéries, } \\
\text { «microcells» }\end{array}$ & oui & élevé & non \\
\hline $\begin{array}{l}\text { Hybridation } \\
\text { in situ }\end{array}$ & ciblée & très bonne & bonne & $\begin{array}{l}\text { virus, bactéries, } \\
\text { «microcells» }\end{array}$ & oui & élevé & non \\
\hline Sérologie & ciblée & bonne & moyenne & virus, bactéries & oui & modéré & non \\
\hline
\end{tabular}

ELISA : Enzyme-linked immunosorbent assay ; PCR : Polymerase Chain Reaction ; RT-PCR : Reverse-transcriptase-PCR ; RFLP : Restriction fragments length polymorphism.

en oeuvre, les délais d'éxécution et de réponse qu'elle suppose, son coût financier et les possibilités de standardisation auxquelles elle peut se prêter. Une appréciation comparée de l'ensemble de ces caractéristiques, pour les méthodes les plus fréquemment exploitées, est présentée dans le tableau 1. Un dernier élément d'importance est le type d'agents pathogènes auxquels le laboratoire va se trouver confronté. La diversité des propriétés biologiques permet de considérer certaines techniques comme spécialement adaptées aux particularités des divers groupes étiologiques. Ce sont ces aspects qui vont être maintenant détaillés.

\section{1 / Le diagnostic virologique}

La technique de référence pour l'identification virale est la culture cellulaire, qui permet de détecter d'éventuels effets cytopathogènes et de procéder à l'identification des virus par application de méthodes immunologiques. Il existe cependant de nombreux virus qui n'ont jamais pu être cultivés, de sorte que tous les autres types de méthodes ont pu être mis à contribution (tableau 2). Le choix d'une technique dépend largement de l'extériori- sation ou non de signes cliniques, du stade d'évolution de l'infection et de la nature des prélèvements obtenus. $\mathrm{Ce}$ dernier point devient crucial lorqu'il s'agit de détecter des animaux porteurs ou de contrôler des géniteurs soupçonnés d'infection par un virus à transmission verticale comme celui de la Nécrose Pancréatique Infectieuse (NPI).

Si l'on prend pour référence les rhabdoviroses, toutes les techniques, sauf la sérologie, conviennent pour opérer le diagnostic sur des individus malades en phase clinique. Pour le contrôle des géniteurs les méthodes histologiques et dérivées ne conviennent plus, mais le recours à la sérologie peut être intéressant. Il en va de même pour la détection de poissons porteurs, la PCR opérée sur matériel biologique risquant par contre, dans ce cas, de se heurter à des phénomènes d'inhibition. Les alphaviroses des salmonidés fournissent une autre illustration de l'adéquation des techniques envisagées en fonction de l'évolution de l'infection et du stade de la maladie (figure 1). On remarquera d'après ces exemples que la sérologie peut apporter d'utiles services lorsqu'on se propose de réaliser une enquête de type rétrospectif en dehors de tout épi- sode clinique, ceci bien que sa reconnaissance officielle comme méthode recommandable tarde à venir.

Pour le diagnostic des virus infectant les invertébrés aquatiques, la sérologie ne peut pas être mise en oeuve du fait de l'absence de production d'anticorps chez les espèces considérées. De même, l'absence de lignées cellulaires homologues ne permet pas l'observation d'effets cytopathogènes en culture cellulaire. Dans ce contexte, la microscopie électronique à transmission reste une technique d'importance, particulièrement dans le cas d'une maladie virale émergente. L'histologie est aussi utilisée pour le diagnostic de certaines maladies virales chez les crustacés dans la mesure où des lésions cellulaires caractéristiques (présence de corps d'inclusion) visibles en microscopie photonique sont observables. Enfin, pour les virus bien caractérisés, les outils moléculaires sont des outils de diagnostic de choix de plus en plus fréquemment utilisés.

\section{2 / Le diagnostic bactériolo- gique}

L'isolement en milieu de culture peut également être considéré comme la 
Tableau 2. Méthodes de diagnostic couramment appliquées au diagnostic des infections virales et bactériennes.

\begin{tabular}{|c|c|c|}
\hline Organismes & Méthodes & Notes \\
\hline \multirow[t]{6}{*}{ Virus } & Culture cellulaire & $\begin{array}{l}\text { effet cytopathogène sur lignées cellulaires } \\
\text { (technique de référence quand elle est possible) }\end{array}$ \\
\hline & Histopathologie & $\begin{array}{l}\text { applications limitées } \\
\text { (AIS, NPI, herpèsvirose de l'huître) }\end{array}$ \\
\hline & Electro-microscopie & parfois, en coloration négative \\
\hline & $\begin{array}{l}\text { Sérologie } \\
\text { Immunodiagnostic }\end{array}$ & $\begin{array}{l}\text { possible mais non "officielle" pour les rhabdovirus } \\
\text { séroneutralisation, immunofluorescence, ELISA, immuno- } \\
\text { histochimie }\end{array}$ \\
\hline & \multirow[t]{2}{*}{ Outils moléculaires } & PCR et RT-PCR, \\
\hline & & Hybridation in situ (surtout virus de Mollusques) \\
\hline \multirow[t]{8}{*}{ Bactéries } & \multicolumn{2}{|c|}{$\begin{array}{l}\text { Isolement et culture } \\
\text { (= technique de référence, mais beaucoup de bactéries sont exigeantes) }\end{array}$} \\
\hline & complétée par & $\begin{array}{l}\text { étude des caractères culturaux et enzymatiques } \\
\text { emploi de galeries miniaturisées } \\
\text { antibiogramme (en cas de maladie déclarée) }\end{array}$ \\
\hline & Culture cellulaire & Piscirickettsia \\
\hline & Colorations sur lames & Gram, Ziehl-Neelsen \\
\hline & Histopathologie & agents non cultivables et non connus \\
\hline & Séro-diagnostic & agglutination, hémagglutination \\
\hline & Immunodiagnostic & $\begin{array}{l}\text { immunofluorescence, ELISA (surtout en criblage), } \\
\text { immuno-histochimie }\end{array}$ \\
\hline & Outils moléculaires & PCR et PCR ancrée, hybridation in situ \\
\hline
\end{tabular}

AIS : Anémie Infectieuse du saumon ; NPI : Nécrose Pancréatique Infectieuse ; ELISA, PCR, RT-PCR : cf. tableau 1.

Figure 1. Alphavirose de la truite arc-en-ciel : choix des méthodes de diagnostic en fonction de l'évolution de la charge infectieuse et de la réponse humorale (IHC, immuno-histochimie ; RT-PCR, reverse-transcriptase PCR).

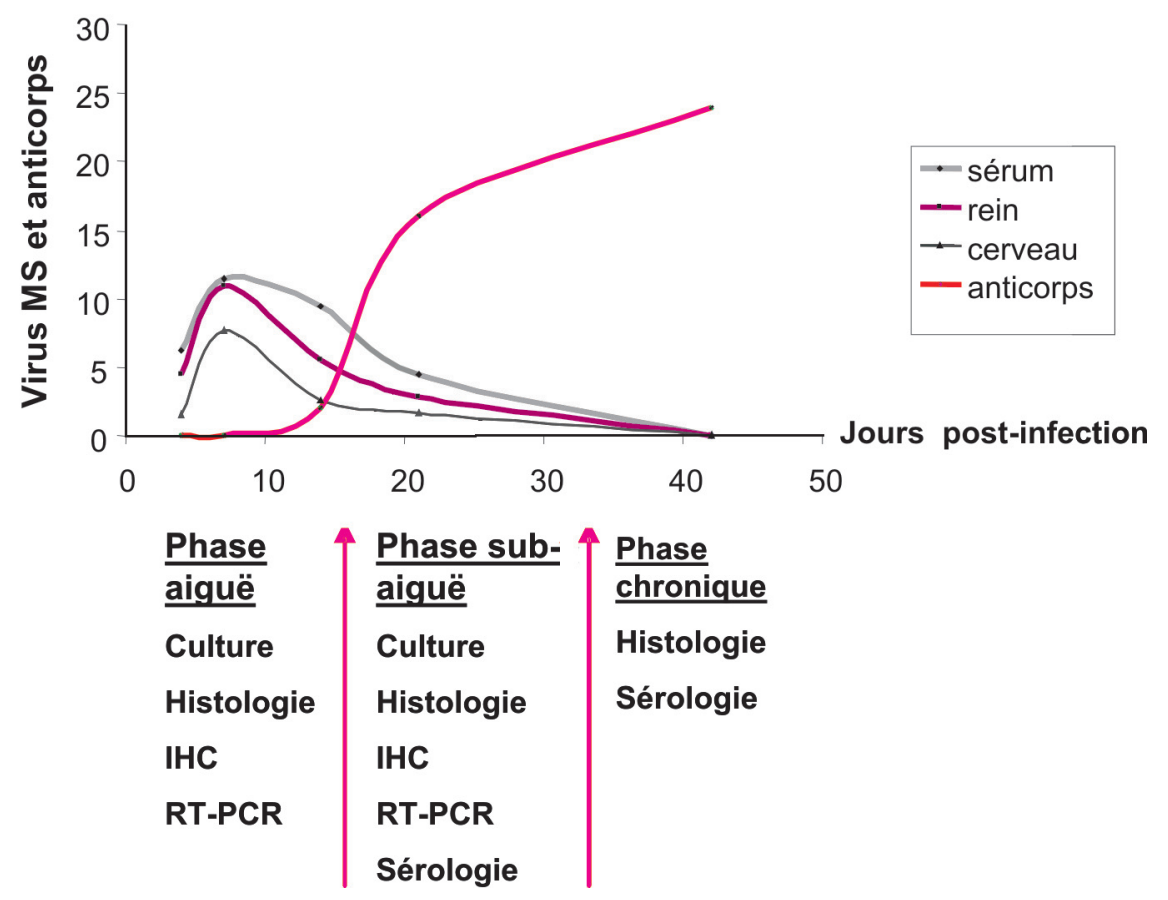

méthode de référence pour la plupart des agents de maladies microbiennes. N'exigeant généralement que des milieux artificiels, il offre beaucoup moins de difficultés que la culture en cellules et représente de surcroît une étape indispensable pour l'étude des caractères culturaux et enzymatiques, l'emploi de galeries miniaturisées et l'évaluation de la sensibilité aux antibiotiques qui sont classiquement à la base du diagnostic microbiologique. Cela ne préjuge pas, bien entendu, de l'existence d'espèces non cultivables, ou aptes à pousser seulement en systèmes cellulaires, comme le sont les Piscirickettsia et les chlamydiales. Par ailleurs, il est important de noter qu'une certaine variabilité phénotypique est observée pour différentes espèces bactériennes en milieu aquatique et que les approches classiques d'identification basées sur l'utilisation de galeries peuvent poser des problèmes d'interprétation. Dans ce cadre, le développement et l'utilisation d'outils moléculaires spécifiques apparaissent comme très utiles. 
Tableau 3. Critères d'appréciation de quelques méthodes couramment employées dans le diagnostic de Renibacterium salmoninarum (d'après Pascho et al 2002).

\begin{tabular}{|c|c|c|c|c|c|c|}
\hline \multirow[b]{2}{*}{ Critères } & \multicolumn{6}{|c|}{ Méthode de diagnostic } \\
\hline & Culture & $\begin{array}{l}\text { FAT }^{a} \text { sur } \\
\text { calque }\end{array}$ & MF-FAT ${ }^{a}$ & $\begin{array}{c}\text { ELISA }{ }^{a} \text { de } \\
\text { terrain }\end{array}$ & $\begin{array}{l}\text { ELISA }{ }^{a} \text { en } \\
\text { laboratoire }\end{array}$ & $\mathrm{PCR}^{\mathrm{a}}$ \\
\hline Spécificité & Non & Oui & Oui & Oui & Oui & Oui \\
\hline Sensibilité & Faible/élevée $^{b}$ & Modérée & Elevée & Faible & Modérée/élevée ${ }^{\mathrm{c}}$ & Elevée \\
\hline Quantification & Non/Oui ${ }^{d}$ & Semi- & Oui & Non & Semi- & Non/Oui ${ }^{e}$ \\
\hline $\begin{array}{l}\text { Détection de } \\
\text { cellules viables }\end{array}$ & Oui & Non & Non & Non & Non & Non/Oui ${ }^{f}$ \\
\hline $\begin{array}{l}\text { Sacrifice des } \\
\text { poissons testés }\end{array}$ & Oui $^{g}$ & Non & Oui $^{9}$ & Non & Oui ${ }^{h}$ & Oui ${ }^{g, h}$ \\
\hline $\begin{array}{l}\text { Rapidité du test } \\
(\leq 2 \text { jours })\end{array}$ & Non & Oui & Oui & Oui & Oui & Oui \\
\hline $\begin{array}{l}\text { gains de temps } \\
\text { /coût sur grands } \\
\text { échantillons }\end{array}$ & Non & Non & Non & Non & Oui & Non \\
\hline $\begin{array}{l}\text { Equipements } \\
\text { spéciaux requis }\end{array}$ & Non & Oui & Oui & Non & Oui & Oui \\
\hline $\begin{array}{l}\text { Expertise } \\
\text { technique requise }\end{array}$ & Non & Modérée & Modérée & Non & Oui & Oui \\
\hline $\begin{array}{l}\text { Réactifs } \\
\text { commercialisés }\end{array}$ & Oui & Oui & Oui & Oui & Oui & $\begin{array}{c}\text { A la } \\
\text { demande }\end{array}$ \\
\hline
\end{tabular}

a FAT : immunofluorescence ; MF-FAT : immunofluorescence après filtration sur membrane (pour liquide coelomique) ; ELISA : enzyme-linked immunosorbent assay ; PCR : polymerase chain reaction; b La présence d'autres organismes dans l'échantillon peut réduire la sensibilité ; c Sérums polyclonaux préférables aux anticorps monoclonaux ; d Méthodes par étalement sur boîte ou inoculation en gouttes ; e Cas de la RT-PCR ; ${ }^{f}$ PCR adaptée à la détection des mRNA seulement ; g A partir du liquide coelomique ; $\mathrm{h}$ A partir du sang.

Comme pour les virus, de nombreuses méthodes ont été prônées pour améliorer les délais de diagnostic ou la détection des animaux porteurs asymptomatiques (tableau 2). Les critères de choix, dans l'application de ces méthodes, sont là encore liés au contexte d'expression clinique ou de surveillance, ainsi qu'à la nature des prélèvements étudiés. Davantage que les virus, les bactéries pathogènes peuvent être concurrencées, selon qu'on s'intéresse à des organes internes, à des lésions cutanées, ou encore à des lots d'oeufs, par une flore saprophyte qui se développe rapidement et ne laisse pas d'interférer dans la mise en pratique de certaines techniques. C'est en particulier le cas en culture et dans les tentatives d'amplification de gènes par PCR. Il est juste d'insister, à l'inverse, sur le fait que les techniques d'identification moléculaire appliquées à des bactéries obtenues en culture pure acquièrent une valeur de certitude qu'elles sont loin d'avoir dans le cas des milieux biologiques complexes.

Une récente mise au point (Michel et al 2005) portant sur Renibacterium salmoninarum, responsable d'une des infections à transmission verticale les mieux documentées, a fourni l'occasion de préciser l'importance du matériel à analyser pour détecter les infections latentes d'adultes destinés à la reproduction. Quelles que soient les techniques appliquées, les organes internes (qui obligent au sacrifice des animaux) et le liquide coelomique (pour les seules femelles) fournissent des résultats très supérieurs à l'échantillonnage des gamètes ou des oeufs. La rénibactériose est sans doute la maladie bactérienne à propos de laquelle les plus nombreuses méthodes de détection et les études comparatives les plus abondantes ont été publiées. Le tableau 3, élaboré d'après Pascho et al (2002), permet de s'en faire une idée.

\section{3 / Le diagnostic des parasites}

$\mathrm{Au}$ sens large, toutes les approches sont utilisables et peuvent être appliquées en parasitologie, en tenant compte, bien entendu, de la nature des organismes soupçonnés. On constate cependant que l'adaptation des tech- niques modernes d'identification aux parasites a demandé plus de temps pour passer en pratique que dans le cas des virus et des bactéries. Cela s'explique si l'on considère qu'une grande partie des organismes incriminés appartiennent aux champignons ou à des formes apparentées, auxquelles les approches de la microbiologie peuvent s'appliquer sans trop de difficultés, ou à des groupes d'eucaryotes dont la taille se prête aux observations morphologiques.

C'est surtout du monde des mollusques, sensibles à de nombreuses formes de parasites protozoaires réfractaires à toute mise en culture et dont la taxonomie est longtemps restée controversée que sont venues des impulsions majeures dans la mise au point de techniques histochimiques ou moléculaires spécifiques. Ainsi, si l'histopathologie reste encore aujourd'hui la technique la plus utilisée dans les laboratoires impliqués dans le contrôle et la surveillance des maladies chez les coquillages, les outils moléculaires y trouvent de plus en plus leur place (figure 2). En effet, leur emploi compense la lourdeur de 
Figure 2. Fréquence d'emploi de différentes méthodes de diagnostic des maladies des mollusques dans les laboratoires nationaux de référence européens.

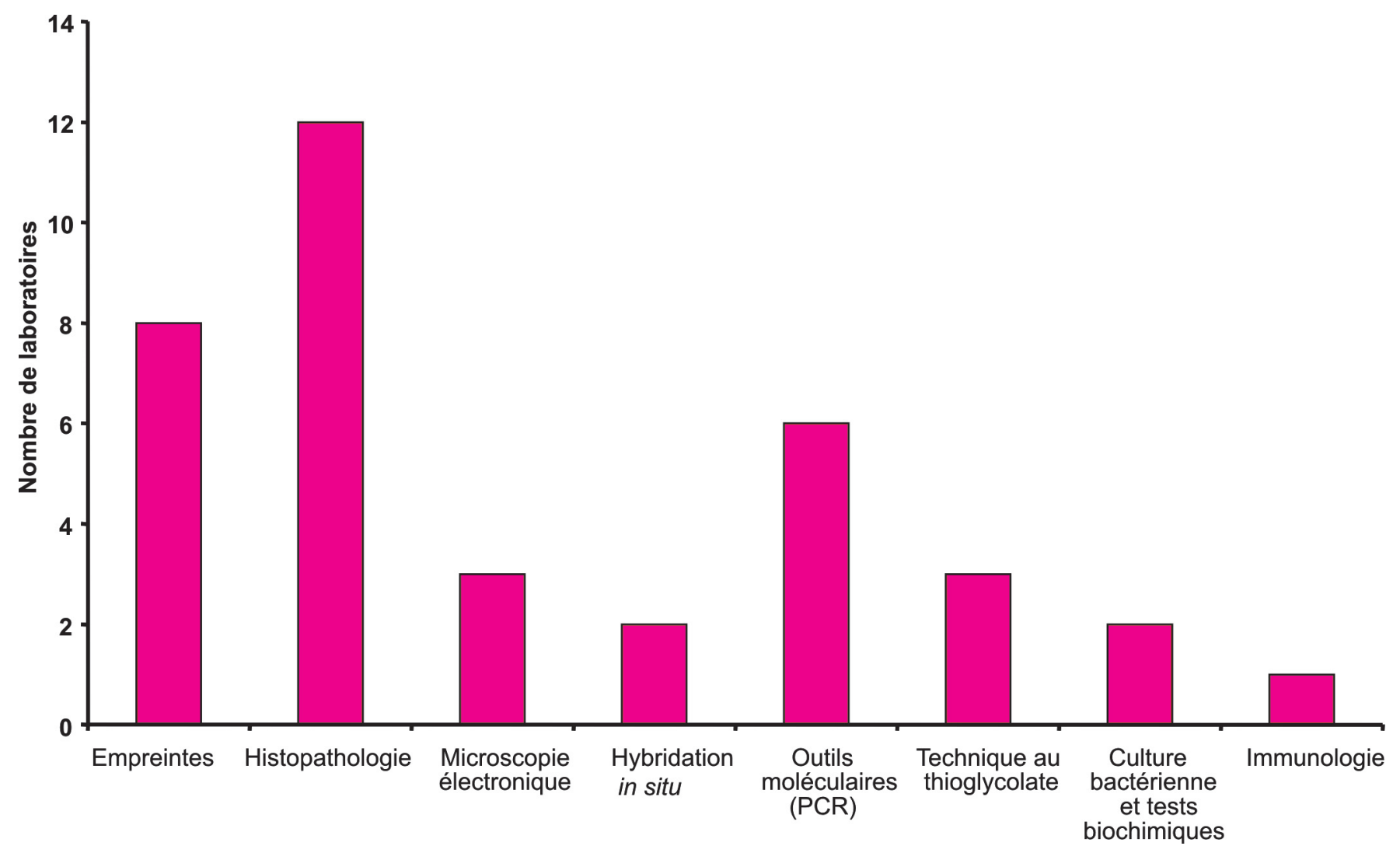

l'histologie et permet un diagnostic précis d'espèce là où d'autres techniques ne permettent pas d'aller plus loin qu'une identification du genre. Chez les crustacés, les dominantes pathologiques sont davantage le fait de virus, dont l'étude s'est toujours heurtée à des difficultés d'obtention de lignées cellulaires homologues. La variété des techniques adoptées pour contourner ce handicap reflète des emprunts qui ressortent tout autant du domaine des virus de poissons que de celui des mollusques (tableau 4). Un aspect original de la pathologie des crustacés reste le recours au diagnostic par bioessai, relativement facile à improviser sur des crevettes pour peu qu'on dispose d'animaux sains.

\section{3 / Exemples de stratégies dans le choix des méthodes de diagnostic}

Il existe beaucoup de documentation accessible, dans la littérature et sur internet, pour guider les démarches de diagnostic en pathologie aquacole. Nous nous contentons de donner des exemples tirés du Code (OIE 2005) et du Manuel (OIE 2006) de l'Office International des Epizooties, qui ont l'intérêt d'illustrer les différences de choix méthodologiques ou techniques déjà évoquées selon qu'on s'adresse aux poissons osseux (tableau 5), aux mollusques ou aux crustacés (tableau 4) et qui, portant sur des organismes faisant l'objet de préocupations de lutte collective, tiennent compte des différentes philosophies pouvant commander les opérations. Se pose alors concrètement la question : comment choisir la ou les méthodes les mieux adaptées à une situation donnée?

\section{1 / Diagnostic clinique}

Dans un contexte de simple identification, lié à l'apparition d'une situation clinique, la priorité sera généralement donnée à des technniques spécifiques, la sensibilité n'étant pas un facteur limitant puisque la question de l'échantillonnage se pose rarement et qu'on dispose en abondance de matériel infecté. La méthode de réference, quand elle est possible, reste toujours la culture des agents responsables.

\section{2 / Détection et surveillance}

Dans la perspective du contrôle sanitaire, les analyses sont souvent conduites en aveugle sur de grands échantillons collectés à partir de populations apparemment en bonne santé. Non seulement les résultats dépendent de la proportion d'animaux éventuellement infectés (prévalence réelle) mais les conséquences légales imposent pratiquement une obligation de résultat. Des techniques hautement sensibles seront préférées s'il s'agit de passer au crible des prélèvements adressés en nombre important. La sensibilité étant rarement conciliable avec une excellente spécificité, les risques de réactions faussement positives ne peuvent en tel cas être négligés, de sorte que si les conclusions $\mathrm{du}$ laboratoire doivent servir d'argument à la prise de décisions réglementaires ou judiciaires il est d'usage de confirmer les cas positifs en recourant, en seconde intention, à une technique plus spécifique et reposant sur un principe différent de la première. On oppose ainsi une étape de diagnostic présomptif, adaptée aux grands échantillons et privilégiant la sensibilité, à un diagnostic de certitude réclamant le plus souvent l'emploi complémentaire d'une deuxième méthode.

La caractère présomptif ou définitif du diagnostic obtenu par certains outils peut, on l'a vu, varier selon la nature du matériel traité : les modalités d'extraction (antigènes ou matériel nucléique) sont déterminantes dans l'application 
Tableau 4. Méthodes recommandées pour le diagnostic des agents de maladies des Invertébrés.

\begin{tabular}{|c|c|c|c|c|c|c|c|}
\hline & culture & MO & Histopathol. & EM & Immunodiagnostic & D. moléculaire & autres \\
\hline \multicolumn{8}{|l|}{ Mollusques } \\
\hline \multicolumn{8}{|l|}{ Virus } \\
\hline Herpèsvirus & & & + & & + & PCR, ISH & \\
\hline \multicolumn{8}{|l|}{ Bactéries } \\
\hline Vibrio spp. & + & & & + & + & PCR & \\
\hline Nocardiose & + & + & & & & PCR, ISH & \\
\hline Withering syndrome & & & + & + & + & PCR, ISH & \\
\hline \multicolumn{8}{|l|}{ Protozoaires } \\
\hline Bonamia & & + & + & + & & PCR, ISH & \\
\hline Mikrocytos & & + & + & + & & & \\
\hline Haplosporidium & & + & + & & & PCR, ISH & \\
\hline Marteilia & & + & + & + & & PCR, ISH & \\
\hline Perkinsus & + & + & + & + & & PCR & \\
\hline \multicolumn{8}{|l|}{ Crustacés } \\
\hline \multicolumn{8}{|l|}{ Virus } \\
\hline Syndrome Taura & & + & + & + & + & RT-PCR, ISH & bioessai \\
\hline White Spot D. & & + & + & + & + & PCR, ISH & bioessai \\
\hline Yellow Head D. & & & + & + & + & RT-PCR, ISH & \\
\hline Baculoviroses & + & + & + & + & & PCR, ISH & bioessai \\
\hline IHHN & & & + & + & & PCR, ISH & bioessai \\
\hline Spawner mortality disease & & & & + & & à l'essai & bioessai \\
\hline \multicolumn{8}{|l|}{ Oomycètes } \\
\hline Aphanomyces invadans & + & & & & & PCR (expérimentale) & bioessai \\
\hline
\end{tabular}

MO : microscope optique ; EM : électromicroscopie ; ISH : hybridation in situ ; IHHN : infectious hypodermal and hematopoietic necrosis ; PCR, RT-PCR : cf. tableau 1

Tableau 5. Méthodes recommandées pour le diagnostic des agents de maladies de poissons listées par l'OIE.

\begin{tabular}{|c|c|c|c|c|c|c|}
\hline & Culture & MO & Histopathol. & Immunodiagn. & Diagn. moléculaire & Autres \\
\hline \multicolumn{7}{|l|}{ Virus } \\
\hline NHE & $+(\mathrm{SN})$ & & & FAT, ELISA & PCR & \\
\hline $\mathrm{NHI}$ & $+(\mathrm{SN})$ & & & FAT, ELISA & PCR, sonde ADN & \\
\hline OMV & $+(\mathrm{SN})$ & & & FAT, ELISA & PCR & \\
\hline VPC & + & & & FAT, ELISA & & \\
\hline SHV & $+(\mathrm{SN})$ & & & FAT, ELISA & RT-PCR & \\
\hline CCVD & $+(\mathrm{SN})$ & & & FAT, ELISA & PCR & \\
\hline ERV & + & & & FAT, IHC & RT-PCR & \\
\hline NPI & $+(\mathrm{SN})$ & & & FAT, ELISA, IHC & & \\
\hline AIS & + & & + & FAT & PCR & \\
\hline RSIV & + & & & FAT & PCR & \\
\hline WSIV & $+(\mathrm{SN})$ & & + & FAT, IHC & & \\
\hline \multicolumn{7}{|l|}{ Oomycètes } \\
\hline Aphanomyces invadans & + & & + & & PCR (expérim.) & \\
\hline \multicolumn{7}{|l|}{ Bactéries } \\
\hline Renibacterium salmoninarum & + & + & & FAT, ELISA & nested-PCR & \\
\hline Edwardsiella ictaluri & + & + & & FAT, ELISA & PCR & \\
\hline Piscirickettsia spp. & + & & + & FAT, IHC & PCR & \\
\hline \multicolumn{7}{|l|}{ Monogènes } \\
\hline Gyrodactylus salaris & & & & & PCR, sonde ADN & morphologie \\
\hline
\end{tabular}

NHE : nécrose hématopoiëtique épizootique ; NHI : nécrose hématopoiëtique infectieuse ; OMV : herpèsvirose du saumon masou ; VPC : virémie printanière de la carpe ; SHV : septicémie hémorragique virale ; CCVD : herpèsvirose du poisson-chat ; ERV : encéphalopathie et rétinopathie virale ; NPI : nécrose pancréatique infectieuse ; AIS : anémie infectieuse du saumon ; RSIV : iridovirose de la dorade japonais ; WSIV : iridovirose de l'esturgeon blanc.

MO : microscopie optique ; IHC : immuno-histochimie ; SN : séroneutralisation ; FAT, ELISA, PCR, RT-PCR : cf. tableaux 1 et 3. 
des techniques reposant sur des sondes ou des réactifs immunologiques ou moléculaires. Il importe donc de les normaliser autant que possible et surtout de les valider, exigences que ne facilite pas l'accessibilité souvent limitée et très variable selon les agents infectieux à des réactifs appropriés. $\mathrm{Ce}$ sont surtout les laboratoire de référence (nationaux, européens, ou cautionnés par les organismes internationaux) qui peuvent en cette matière apporter un appui déterminant en fournissant matériels, documents et conseils, contribuant ainsi à la résolution des nombreuses difficultés qui obèrent encore la qualité des diagnostics.

\section{Conclusions : défis et besoins futurs}

Les bioagresseurs évoluent, parfois rapidement, en réponse aux pressions de sélection résultant de la lutte menée contre leur propagation. On observe un accroissement régulier des descriptions d'agents pathogènes, tandis que nos progrès dans la compréhension des mécanismes de virulence tendent à introduire un certain assouplissement des conceptions classiques et à réduire parfois à peu d'éléments les différence entre les formes pathogènes vraies ou opportunistes et les formes non pathogènes d'un même agent. Face à ces tendances, face à des exigences de précision toujours accrues, il est probable que le diagnostic soit appelé à évoluer lui aussi. Il pourrait s'adresser non plus à des espèces mais à des variants pathogènes en mettant l'accent, notamment chez les bactéries, sur la détection de particularités biologiques ou génétiques qui pourront être des marqueurs ou des critères de virulence, voire des marqueurs de résistance aux substances thérapeutiques. La clé d'une telle évolution passe nécessairement par l'amélioration et le renforcement des méthodes de détection moléculaire et par la mise au point de systèmes de typage.

Un autre problème d'actualité est celui des maladies émergentes, qui dans un contexte d'échanges commerciaux intenses semblent bien se banaliser, mais face auxquelles les laboratoires apparaissent dramatiquement impuissants à réagir dans leur schéma d'organisation traditionnel. Faute de connaissances précises sur les agents étiologiques en cause, de réactifs appropriés, voire d'expérience et de compétences spécialisées, les délais de réponse peuvent devenir trop longs. Ils posent la question de la souplesse et de la réactivité des structures spécialisées et des systèmes de surveillance, qui devront sans doute s'organiser en réseaux supra-nationaux et veiller à une efficace circulation de l'information pour faire face à ces nouvelles menaces. C'est au final dans une double perspective, celle de l'adaptation et de l'optimisation des techniques de détection et celle des approches épidémiologiques intégrées, que semblent devoir s'inscrire les préoccupations de recherche susceptibles de répondre aux exigences du diagnostic.

\section{Références}

Michel C., Elliott D., Jansson E., Dalsgaard I, Urdaci M., Midtlyng P., 2005. Broodfish testing for bacterial infections. Workpackage 4 report, EC project VESO-1601 «Fish Egg Trade», VESO, Norway, 20p.

O.I.E., 2005. Code sanitaire pour les animaux

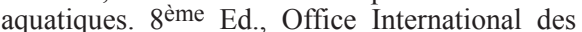
Epizooties, Paris, France (http://www.oie.int).
O.I.E. 2006. Manual of diagnostic tests for aquatic animals. 5 ème Ed., Office International des Epizooties, Paris, France (http://www. oie.int).

Pascho R.J., Elliott D.G., Chase D.M., 2002. Comparison of traditional and molecular methods for detection of Renibacterium salmoninarum. In : Molecular diagnosis of salmonid diseases, Cunningham C.O. (Ed), Kluwer Academic Publishers, Dordrecht, 157-209.

\section{Résumé}

Les agents pathogènes présents dans les milieux aquatiques peuvent exercer leurs méfaits dans tous les types d'élevage et sur toutes sortes d'espèces vertébrées ou invertébrées. Leur diagnostic a longtemps été handicapé par le manque de connaissances taxonomiques relatives aux organismes d'intérêt médical ou vétérinaire, mais les progrès accomplis en ce domaine avec le développement des approches génétiques et moléculaires permettent de disposer désormais d'un arsenal de techniques adaptées à toutes les situations. Leur emploi est dicté par le contexte clinique, sanitaire, voire réglementaire dans lequel s'inscrit la demande et par la priorité accordée à l'identification ou à la détection des organismes pathogènes. La revue critique des techniques accessibles aux laboratoires permettra d'aborder les questions posées par l'évolution de la pathologie aquacole et d'envisager quelques réponses qu'il serait possible d'apporter. 


\begin{abstract}
Diagnostic techniques in the health of fish-farming species : interest and limits

A great variety of pathogenic organisms present in the water may affect the vertebrate and invertebrate species cultured in different aquatic habitats. Compared to humans and terrestrial species, the diagnostic of aquatic animal diseases has long been hampered by scarce taxonomic knowledge about the relevant pathogens, but advances resulting from genetic and molecular developments has now resulted in a complete panoply of suitable techniques for this purpose. Choosing a diagnostic method should be done according to clinical, sanitary or officially prescribed considerations, and also according to the purpose of the procedure, should it be the correct identification or the detection of a pathogen. A critical overview of the techniques available of common use in diagnostic laboratories is presented. This will permit to discuss emergent problems resulting from the aquaculture transformation and to suggest some appropriate responses to these problems.
\end{abstract}

MICHEL C., BERNADET J.-F., CASTRIC J., JOLY J.-P., 2007. Les techniques de diagnostic en santé des espèces aquacoles : intérêt et limites. INRA Prod. Anim., 20, 191-198. 